\title{
Misconduct in Clinical Research in India: Perception of Clinical Research Professional in India
}

\section{Madhuri Patel ${ }^{*}$}

Texila American University, Guyana, South America

*Corresponding author: Madhuri Patel, Texila American University, Guyana, South America, Tel: 9558196458; E-mail: madhuri.patel1988@gmail.com

Received date: April 05, 2017; Accepted date: May 04, 2017; Published date: May 09, 2017

Copyright: () 2017 Patel M. This is an open-access article distributed under the terms of the Creative Commons Attribution License, which permits unrestricted use, distribution, and reproduction in any medium, provided the original author and source are credited.

\begin{abstract}
Misconduct in clinical research is an unfortunate reality and widespread. Researchers are expected to conduct research and report results honestly. However, that is not how clinical trials always get done. Good Clinical Practice (GCP) guideline is adopted internationally as a standard operating process for purpose of conducting, recording or reporting clinical trials. However, unavailability of international harmonized framework for misconduct management makes clinical research industry vulnerable to commit misconduct. Most of the cases of misconduct are probably not published. They are not recognized or covered up altogether. Misconduct and fraud can be due to any reasons and of various types. In all circumstances, any misconduct should be handled strictly and related regulations should be at place to prevent occurrences. Very few cases of scientific misconducts have been identified or reported in India. However, there is no evidence that all clinical trials conducted in India meet ethical standards and misconduct does not exist. Rather it is more likely that the scientific misconduct amongst researcher have not been systematically investigated. This article discusses the possible reasons for the occurrence of scientific misconduct and explores options, which can possibly help prevent such instances.
\end{abstract}

Keywords: Bioethics; Ethics; Medical research; Clinical trial; Clinical Research; Misconduct; Fraud

\section{Introduction}

Clinical Research is the cornerstone of scientific research and healthcare innovation. It has the potential to create a better state of health. Therefore it is important that clinical research is free from bias, fraud and misconduct. Everyone involved in conducting clinical trials must abide by the moral and ethical obligations as outlined by Nuremberg code [1] and Declaration of Helsinki 1963 (later revised in 2013) $[2,3]$. Scientific medical research has a long history of fraud and misconduct despite of the morality underpinning medical research $[4,5]$. Despite the publication of misconduct in the media and role of regulatory governance through the globe, misconduct has often been underreported [6-9]. One of the unanswered questions is how commonly it occurs, and the answer depends on how misconduct is defined. The major reason for this could be the fact that there is no standard definition of what constitutes research dishonesty [5], making it more difficult to identify and classify the cases and so to prevent them. To understand this, the definitions available from various sources are discussed in this article.

The Oxford English Dictionary describes fraud as "wrongful or criminal deception intended to result in financial or personal gain" and deceit as "the action or practice of deceiving someone by concealing or misrepresenting the truth" [10]. Research organizations and the literature have defined these behavioural patterns within the umbrella title of "Research Misconduct."

United States commission on Research Integrity produced a definition [11]. At the end of 2000, the federal government produced a slightly shorter definition, with long footnotes, together with requirements for a finding of misconduct [12]. The definition states:
Research misconduct is defined as fabrication, falsification, or plagiarism in proposing, performing, or reviewing research, or in reporting research results.

Fabrication is making up data or results and recording or reporting them.

Falsification is manipulating research materials, equipment, or processes, or changing or omitting data or results such that the research is not accurately represented in the research record.

Plagiarism is the appropriation of another person's ideas, processes, results or words without giving appropriate credit.

The definition continues by making clear that 'research misconduct does not include honest error or differences of opinion'.

A finding of research misconduct depends on three requirements. First, there must be 'a significant departure from accepted practices of the relevant research community'. Secondly, the misconduct must be 'committed intentionally or knowingly, or recklessly'. Thirdly, the allegations must be proved 'by a preponderance of evidence' [13].

A British consensus conference held in Edinburge in 2000 has produced still broader definition that is 'Behaviour by a researcher, intentional or not, that falls short of good ethical and scientific standards' [13]. This definition is not including about classification such as 'seriously' or 'significantly' short of good standards and does not depend on intention.

The Medical Research Council (MRC) definition of misconduct and fraud (or a variation of the MRC code) is widely used. This code states the following definition: The fabrication, falsification, plagiarism or deception in proposing, carrying out or reporting results of research or deliberate, dangerous or negligent deviations from accepted practices in carrying out research. It includes failure to follow established protocols if this failure results in unreasonable risk or harm to humans, 
Page 2 of 9

other vertebrates or the environment and facilitating of misconduct in research by collusion in, or concealment of, such actions by others. It also includes intentional, unauthorized use, disclosure or removal of, or damage to, research-related property of another, including apparatus, materials, writings or devices used in or produced by the conduct of research. It does not include honest error or honest differences in the design, execution, interpretation or judgement in evaluating research methods or results or misconduct unrelated to the research process. Similarly it does not include poor research unless this encompasses the "intention to deceive" (MRC, 1997) [14].

The MRC definition of misconduct is most suitable for India. It clearly states what action can be considers as misconduct and what cannot be. It makes evaluation of misconduct streamlined and clear process can be established based on the definition. It also helps to classify the misconduct according to their type.

Leadership of national regulatory body is required to respond to the problem of clinical research misconduct. It includes provide guidelines on good practice, teach ethical practice and encourage research, offer help for the investigation of misconduct and raise consciousness about the problem. Problem with local bodies such as university and hospital with dealing with research misconduct is that they often lack competence, conflict of interest and sometimes commitments that they fear that further investigation and reporting may humper the institute's reputation. The main importance of responding to clinical research misconduct should be on improving overall level of scientific integrity, rather than only on investigating suspected cases. India need codes of good practice rather than simply enlist bad practices to be avoided. Researchers need to teach integrity rather than warning against dishonesty. Once consciousness is raised, researcher and anyone involved in conducting clinical trials will realize that they are constantly presented with ethically difficult question around such as conflict of interest, informed consent, data analysis, authorship and many more issues. There is no rulebook to find right answer for all ethical issues. Rather, researcher needs to be able to think their way through the complexities to reach an ethically defensible answer. They may often need help and they should not be afraid to ask for it.

Reports of misconduct by medical practitioners engaged in research go back for at least a century $[15,16]$. Since World War II there have been repeated periods when serious concerns have been expressed about unethical conduct in research involving humans. The reports in the 1960s of Beecher from the USA [17] and Pappworth from the UK [18] contributed to the establishment in most western countries in the 1960s of institutional research ethics committees. Lock, Wells and Farthing catalogued a more contemporary history of research misconduct in Fraud and Misconduct in Biomedical Research, now in its third edition [19]. Lock also described a period in the early 1980s as 'bad years' for ethical problems in research. He particularly identified three research scandals emanating from Australia; those of Briggs, McBride [19] and Prasad [20]. In response to these events, there have been reports of inquiries into research misconduct [21], as well as the development of additional international codes of research conduct [22], and the publication of national codes of conduct for research involving humans $[23,24]$. Thus, there is no lack of clearly defined expectations of medical practitioners and biomedical researchers.

This article discusses the possible reasons for the occurrence of scientific misconduct and explores options, which can possibly help prevent such instances.

\section{Method}

The study involved a self-administered survey and was carried out in Texila American University as a dissertation for the $\mathrm{PhD}$ program in clinical research in India. It consisted of 35 questions, covering informed consent, ethics committee reviews, post-trial access to investigational product (drug or device being studied), financial and non-financial conflict of interests, regulatory rules and guidelines, ethical codes and principles, use of placebo, research misconduct (violation of the code of research and ethical behaviour), documentation and clinical researchers' recommendations. The survey questionnaire was peer reviewed by colleagues and guides and experts in the field from Texila American University. The survey elicited responses based on the general experience and opinions of clinical research professionals. Questions related to misconduct in clinical research will be reported in this paper. Snowball sampling (chainreferral sampling) method was used for data collection as respondents were difficult to locate. At the start of data collection, a small group of participants (137) was invited to participate in the survey, and through their networks, other participants who could potentially contribute to the study were located.

A number of clinical researchers were identified and contacted via email and/or telephone and invited to participate in the survey. These participants were then asked to provide information to locate other individuals who were eligible to participate in the survey. The invitation to participate in the survey reached 385 participants. Participants completed the survey online. Data collection took place over five months. No incentive was given to participants. Surveys completed via the Internet were stored in Microsoft excel format. Surveys in which a minimum of $10 \%$ of questions were answered were considered "complete" and were used for data analysis. This database was used to determine the frequency of responses by each variable and descriptive analysis was used.

\section{Result}

A total of 389 surveys were received, of which 385 were considered complete and used for this analysis. The survey was designed such that there were skip patterns for some questions; therefore the number of responses (n) varies for different questions. The respondents are from India and are currently working in the clinical research field. 169/385 (43.9\%) of participants are 36 to 45 years of age, followed by 21 to 35 years $142 / 385(36.9 \%)$ and 46 to 60 years $(74 / 385$ or $19.2 \%)$. Out of 385 participants, $181(47 \%)$ are working at a clinical research site and 162 $(42.1 \%)$ are associated or working with contract research organisations (CROs). 19/385 (4.9\%) of participants are working for ethics committees (EC) and 19/385 (4.9\%) with sponsor companies. These data show that most of the research activities are undertaken by CROs and at research sites. As per current practice, most of the sponsors are outsourcing research activities to CROs, so it is obvious that significantly fewer people from pharmaceutical industries are directly involved in clinical trials. $272 / 385(70.6 \%)$ of participants are postgraduates, $92 / 385$ (23.9\%) have doctoral degrees and 21/385 (5.5\%) are undergraduates. Our data shows that only 101/356 (28.4\%) of respondents have ever served on ethics committees (EC); 255/356 (71.6\%) have never served on an EC.

The data shows that $146 / 385$ (37.9\%) participants have 11 to 15 years of experience in clinical research, while only $10 / 385(2.6 \%)$ have less than 2 years of experience. 236/385 (61\%) of sample had more 
Citation: Patel M (2017) Misconduct in Clinical Research in India: Perception of Clinical Research Professional in India. J Clin Res Bioeth 8: 303.

Page 3 of 9

than 10 years of research experience, and 16/385 (4.2\%) of participants had more than 20 years of experience.

In the questionnaire, participants were asked whether they have ever had formal research ethics training. 233/385 (60.5\%) of participants responded that they have formal research ethics training while 152/385 (39.5\%) have never undergone formal ethics training during their career. Further to that, participants were asked which type of research ethics training they have attended if they have answered yes. It is also possible that a few participants have attended more than one type of training. Figure 1 shows the type of ethics training participants have attended. Our data suggests that it is required to develop research ethics programmes and courses. Online programmes may be more useful as more professionals can benefit and international standards of ethics can be developed.

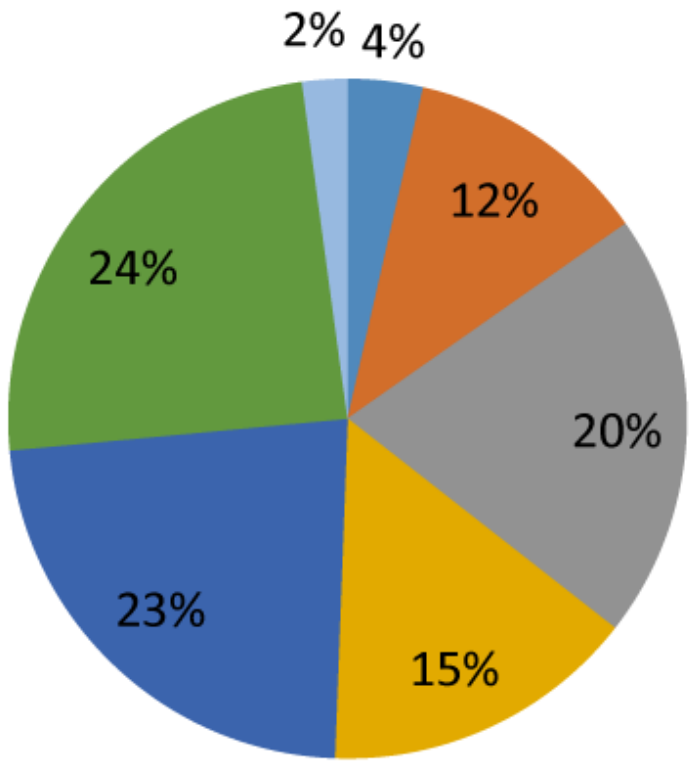

Figure 1: Type of research ethics training participant had attended.
- Research Ethics Course

- Online research ethics training

Research ethics workshop

- Component of professional education

- Component of research methods

- Conference

- Certificate program
Various kind of finding are reported in past few years during audit of clinical trials. After lengthy literature review, we have enlisted all possible audit finding can be reported during audit and asked participants to rate them as per their existence in real world clinical trials in India. Table 1 shows group analysis of rating for audit finding. Majority of participants have rated more to "Failure to follow investigational plan", "Inadequate drug accountability", "Inadequate completion of informed consent forms (ICF)" and "Inadequate IP accountability" as an audit findings at site. Majority of participants have rated more to "Failure to make risk determinations", "Failure to have a non-scientific member during meeting", "Inadequate/Not following Standard Operating Procedures (SOPs)" and "Failure to maintain member rosters" as an audit findings at EC.

\begin{tabular}{|c|c|c|c|c|c|}
\hline & \multicolumn{5}{|l|}{ Median } \\
\hline & CRO (1-10) & EC & Study Site & Sponsor & Other/SMO \\
\hline & & $(1-10)$ & $(1-10)$ & $(1-10)$ & $(1-10)$ \\
\hline \multicolumn{6}{|l|}{ At sites } \\
\hline Inadequate monitoring & $3.0(1-7)$ & $3.0(2-7)$ & $3.0(1-9)$ & $3.0(1-8)$ & $5.0(1-7)$ \\
\hline Failure to follow investigational plan & $5.0(1-8)$ & $5.0(4-8)$ & $5.0(1-8)$ & $5.0(4-7)$ & $3.5(2-6)$ \\
\hline Inadequate and inaccurate records & $3.0(1-9)$ & $3.0(2-7)$ & $4.0(1-9)$ & $4.0(2-8)$ & $3.0(3-5)$ \\
\hline Inadequate drug accountability & $5.0(1-9)$ & $5.0(2-8)$ & $5.0(1-10)$ & $6.0(2-8)$ & $4.5(4-9)$ \\
\hline Inadequate completion of informed consent forms & $5.0(1-9)$ & $5.0(3-8)$ & $5.09(1-9)$ & $5.0(2-8)$ & $5.0(3-6)$ \\
\hline Failure to report $\mathrm{AE}$ & $4.0(1-9)$ & $5.0(4-9)$ & $4.0(1-10)$ & $5.0(1-10)$ & $6.0(1-9)$ \\
\hline
\end{tabular}


Citation: Patel M (2017) Misconduct in Clinical Research in India: Perception of Clinical Research Professional in India. J Clin Res Bioeth 8: 303. doi:10.4172/2155-9627.1000303

Page 4 of 9

\begin{tabular}{|c|c|c|c|c|c|}
\hline Failure to obtain/record patient consent & $2.0(1-9)$ & $2.0(1-9)$ & $2.0(1-9)$ & $2.0(1-6)$ & $7.5(2-8)$ \\
\hline Failure to submit/notify progress reports & $4.0(1-10)$ & $4.0(2-10)$ & $4.0(1-9)$ & $5.0(2-10)$ & $7.0(6-8)$ \\
\hline Failure to notify regulatory, investigator or EC & $2.0(1-9)$ & $2.0(1-7)$ & $2.0(1-9)$ & $3.0(1-8)$ & $7.0(2-9)$ \\
\hline Inadequate IP accountability & $6.0(2-8)$ & $6.0(3-7)$ & $6.0(1-9)$ & $6.0(2-8)$ & $8.0(5-10)$ \\
\hline Failure to obtain signed investigator agreement & $1.0(1-9)$ & $2.0(1-8)$ & $2.0(1-9)$ & $2.0(1-8)$ & $4.0(1-9)$ \\
\hline Inadequate/not following SOPs & $4.0(1-10)$ & $4.0(2-8)$ & $4.0(1-10)$ & $4.0(2-9)$ & $6.5(3-9)$ \\
\hline Failure to obtain regulatory/EC approval & $1.0(1-9)$ & $1.0(1-6)$ & $1.0(1-9)$ & $2.0(1-6)$ & $5.5(1-7)$ \\
\hline Unqualified staff & $3.0(1-8)$ & $3.0(2-7)$ & $3.0(1-9)$ & $4.0(2-8)$ & $6.0(5-7)$ \\
\hline \multicolumn{6}{|l|}{ At ECs } \\
\hline Inadequate meeting minutes & $3.0(1-8)$ & $3.0(2-7)$ & $3.0(1-9)$ & $4.0(1-8)$ & $3.5(5-7)$ \\
\hline Inadequate/not following SOPs & $6.0(1-9)$ & $6.0(4-8)$ & $6.0(1-9)$ & $6.0(3-8)$ & $4.5(1-8)$ \\
\hline $\begin{array}{l}\text { Failure to have majority of members present during convinced } \\
\text { meeting }\end{array}$ & $4.0(1-10)$ & $4.0(2-8)$ & $4.0(1-10)$ & $4.0(2-8)$ & $4.0(2-7)$ \\
\hline Inappropriate use of expedited review & $2.0(1-9)$ & $3.0(2-5)$ & $2.0(1-9)$ & $3.0(1-8)$ & $4.0(1-5)$ \\
\hline Failure to have a non-scientific member during meeting & $5.0(1-9)$ & $5.0(1-8)$ & $5.0(1-9)$ & $5.0(3-9)$ & $2.5(2-8)$ \\
\hline Failure to maintain member rosters & $5.0(1-9)$ & $5.0(2-8)$ & $5.0(1-9)$ & $5.0(1-9)$ & $4.5(3-7)$ \\
\hline Failure to make risk determinations & $7.0(2-9)$ & $7.0(3-8)$ & $7.0(1-10)$ & $4.0(1-8)$ & $6.5(4-9)$ \\
\hline
\end{tabular}

Table 1: Audit findings.

There are few protocol violations repeatedly take place in conduct of data suggests that most frequent protocol violation is "Multiple visits clinical trials. From literature review we have listed all violations and participants to rate them. The group analysis is shown in Table 2. Our

missed or outside permissible windows", "Materially inadequate record keeping" and "Intentional deviation from protocol, GCP, regulations".

\begin{tabular}{|c|c|c|c|c|c|}
\hline \multirow{3}{*}{$\begin{array}{l}\text { Rate the following protocol violations } \\
\text { according to its frequency in common } \\
\text { practice. ( } 1 \text { is minimum and } 10 \text { is maximum) }\end{array}$} & \multicolumn{5}{|l|}{ Median } \\
\hline & \multirow[t]{2}{*}{ CRO (1-10) } & EC & Study Site & Sponsor & Other/SMO \\
\hline & & $(1-10)$ & $(1-10)$ & $(1-10)$ & $(1-10)$ \\
\hline Inadequate or delinquent informed consent & $3.0(2-9)$ & $3.0(2-7)$ & $3.0(2-9)$ & $4.0(108)$ & $3.5(1-9)$ \\
\hline Inclusion/exclusion criteria not met & $3.0(1-9)$ & $4.0(3-8)$ & $4.0(1-9)$ & $4.0(2-7)$ & $3.5(2-8)$ \\
\hline Improper breaking of the blind & $1.0(1-9)$ & $1.0(1-6)$ & $1.0(1-9)$ & $1.0(1-6)$ & $3.5(2-7)$ \\
\hline Use of prohibited medication & $3.0(1-9)$ & $3.0(1-8)$ & $4.0(1-9)$ & $4.0(3-9)$ & $5.0(4-6)$ \\
\hline Incorrect or missing tests & $2.0(1-10)$ & $2.0(2-8)$ & $2.0(1-9)$ & $5.0(1-8)$ & $5.0(4-7)$ \\
\hline Mishandled sample & $3.0(1-9)$ & $3.0(2-9)$ & $3.0(1-9)$ & $5.0(1-10)$ & $3.5(2-7)$ \\
\hline $\begin{array}{l}\text { Multiple visits missed or outside permissible } \\
\text { windows }\end{array}$ & $4.0(1-9)$ & $4.0(2-6)$ & $4.0(1-9)$ & $4.0(1-9)$ & $6.5(3-8)$ \\
\hline Materially inadequate record keeping & $4.0(1-9)$ & $4.0(1-9)$ & $4.0(1-9)$ & $4.0(2-7)$ & $6.5(1-9)$ \\
\hline $\begin{array}{l}\text { Intentional deviation from protocol, GCP, } \\
\text { regulations }\end{array}$ & $4.0(1-9)$ & $4.0(2-8)$ & $4.0(1-8)$ & $4.0(1-8)$ & $8.0(2-10)$ \\
\hline $\begin{array}{l}\text { Subject repeated non-compliance with study } \\
\text { requirements }\end{array}$ & $2.0(1-8)$ & $3.0(2-7)$ & $2.0(1-9)$ & $3.0(2-7)$ & $5.0(3-9)$ \\
\hline
\end{tabular}

Table 2: Protocol violations according to its frequency. 
Citation: Patel M (2017) Misconduct in Clinical Research in India: Perception of Clinical Research Professional in India. J Clin Res Bioeth 8: 303. doi:10.4172/2155-9627.1000303

Page 5 of 9

\begin{tabular}{|l|l|}
\hline What kind of misconduct usually takes place? & Count \\
\hline Total & $379(100.0 \%)$ \\
\hline ICF & $288(76.0 \%)$ \\
\hline Attempt to limit to documents and records & $246(64.9 \%)$ \\
\hline Difficulty scheduling site visit & $56(14.8 \%)$ \\
\hline Source and other documents missing & $55(14.5 \%)$ \\
\hline Data appear to have been altered from what was originally reported & $44(11.6 \%)$ \\
\hline Data appear to have been deliberately omitted or lack of efficacy & $204(53.8 \%)$ \\
\hline Data and results that too consistent & $55(14.5 \%)$ \\
\hline Source data and medical history not matching with CRF & $45(11.9 \%)$ \\
\hline Similar hand-wring for procedures signed as completed by different individuals or vice-a-versa & $108(28.5 \%)$ \\
\hline Significant number of diaries or patient questionnaire in pristine condition & $200(52.8 \%)$ \\
\hline Used ID package/blister in pristine condition & $170(44.9 \%)$ \\
\hline Other & $2(0.5 \%)$ \\
\hline
\end{tabular}

Table 3: Type of Misconduct.

There is different kind of misconduct; out of them few take place very frequently in routine practice. Participant was asked to select all that they feel are frequent misconduct in day to day practice. Our data (Table 3) shows 288/379 (76.0\%) participants have selected that misconduct in "ICF" usually takes place in clinical trials. 246/379 (64.9\%) have selected "attempt to limit to documents and records". 204/379 (53.8\%) and 200/379 (52.8\%) respondents have selected "Data appear to have been deliberately omitted or lack of efficacy" and
"Significant number of diaries or patient questionnaire in pristine condition" respectively. There are few factors motivate misconduct. Participants were asked to rate those reasons due to which misconduct take place. The group analysis of participants' responses to reason for misconduct is shown in Table 4. Our data shows that "Financial interest/conflict of interest" and "Over ambition to become famous" are the most involved reasons for misconducts. These data represent participant's own or witnessed miss conduct.

\begin{tabular}{|c|c|c|c|c|c|}
\hline & \multicolumn{5}{|l|}{ Median } \\
\hline & CRO & EC & Study Site & Sponsor & Other/SMO \\
\hline & $(1-10)$ & $(1-10)$ & $(1-10)$ & $(1-10)$ & $(1-10)$ \\
\hline Over ambition to become famous & $7.0(1-8)$ & $7.0(2-8)$ & $6.5(1-9)$ & $3.0(1-8)$ & $3.0(1-8)$ \\
\hline Financial interest/conflict of interest & $9.0(1-10)$ & $9.0(4-10)$ & $9.0(1-10)$ & $8.0(3-10)$ & $4.5(2-8)$ \\
\hline Laziness of staff involved in clinical trial & $4.0(1-8)$ & $4.0(2-6)$ & $4.0(1-9)$ & $4.0(2-7)$ & $4.5(3-6)$ \\
\hline $\begin{array}{l}\text { Strong belief intuitively in the 'right' } \\
\text { answer despite the available evidence } \\
\text { being contrary }\end{array}$ & $3.0(1-8)$ & $3.0(2-7)$ & $3.0(1-9)$ & $3.0(1-8)$ & $4.5(3-8)$ \\
\hline Innocent ignorance & $3.0(1-10)$ & $3.0(1-6)$ & $3.0(1-9)$ & $4.0(2-9)$ & $5.0(4-7)$ \\
\hline $\begin{array}{l}\text { Discarding sources after } \text { accurate } \\
\text { transcription or creating source } \\
\text { documents from case report form }\end{array}$ & $2.0(1-9)$ & $3.0(1-8)$ & $3.0(1-9)$ & $4.0(1-9)$ & $4.5(2-8)$ \\
\hline Pressures for promotion and tenure & $1.0(1-9)$ & $2.0(1-9)$ & $2.0(1-9)$ & $3.0(1-8)$ & $3.5(2-7)$ \\
\hline Competition among staffs & $3.0(1-9)$ & $3.0(1-7)$ & $3.0(1-9)$ & $4.0(1-9)$ & $5.5(5-8)$ \\
\hline Need for recognition & $4.0(1-10)$ & $4.0(2-7)$ & $4.0(1-9)$ & $4.0(1-10)$ & $5.5(4-9)$ \\
\hline Ego & $2.0(1-9)$ & $2.0(1-6)$ & $3.0(1-10)$ & $3.0(1-10)$ & $6.0(2-10)$ \\
\hline
\end{tabular}


Page 6 of 9

\begin{tabular}{|l|l|l|l|l|l|}
\hline Personality factors & $2.0(1-9)$ & $2.0(1-7)$ & $3.0(1-9)$ & $3.0(1-9)$ & $5.5(2-9)$ \\
\hline $\begin{array}{l}\text { Conflicting personal and professional } \\
\text { obligations }\end{array}$ & $4.0(1-9)$ & $4.0(1-7)$ & $4.0(1-9)$ & $5.0(1-8)$ & $6.0(3-8)$ \\
\hline $\begin{array}{l}\text { Environmental factors such as amount of } \\
\text { oversight of study, existence of explicit } \\
\text { versus implicit rules, penalties and } \\
\text { rewards attached to such rules }\end{array}$ & $1.0(1-9)$ & $2.0(1-8)$ & $2.0(1-9)$ & $5.0(1-10)$ & $6.0(3-8)$ \\
\hline $\begin{array}{l}\text { Regulations involved and insufficient } \\
\text { mentoring }\end{array}$ & $2.0(1-8)$ & $3.0(2-6)$ & $3.0(1-10)$ & $3.0(1-8)$ & $5.0(3-6)$ \\
\hline
\end{tabular}

Table 4: Rate the following reasons for fraud/misconduct (Falsification, fabrication, plagiarism of data or deception in conduct) in clinical trials.

\section{Discussion}

Research is well-known team and "ethics" have acquired very special place in medicine in the last 30-50 years. Until last few decades' science had a best status and scientists were considered more honest than ordinary citizens. However, today better knowledge about bioethics is available to deal with these aspects in theoretical terms. The first aspect of the ethics is concerned with the safety and trust of patients including trial participants and healthy volunteers. The evaluation of unethical practice rests primarily with research ethics committee; however necessary ground depends in the honesty of researcher. The second aspect of ethical or unethical practice is how the researcher recruits subjects: do they fairly present all the undisputed facts to potential subject? And the third aspect is, interpretation of result. Are the results interpreted totally independently of any sponsors of the research? If the results are not interpreted truly for any reason practitioner may be misled in their treatment. In this way, societal values come into picture and serious contact with research activities.

Misconduct and ethics in clinical research is widespread topic. Misconduct involves knowingly failing to comply with regulations protecting research subjects such as falsifying data or documents. Misconduct can be committed by institutions/committees or individuals due to various reason including financial gain. The main purpose of designing ethics committees is to ensure that everyone involved in conduct of clinical trial comply with regulations and controls conflict of interest. However, in some cases, ethics committees may fail to follow their responsibilities [25].

Fraud and misconduct both terms are often used interchangeably, however there is a difference between two. Definition of fraud in court is "the knowing breach of the standard of good faith and fair dealing as understood in the community, involving deception or breach of trust, for money" [25]. The fraud is intentional act to damage another individual or dishonesty made for personal or professional gain, for example misleading reporting of results. Misconduct may not be an intentional action, but an act of poor management or administration. For example, failure to follow approved protocol which can result in unreasonable risk or harm to humans [26]. Fraud should have an element of deliberate action, which is not the case with misconduct.

The reasons and motives for conducting misconduct in clinical research could vary personal to professional. Our data suggests that financial interest and the professional over ambitions to become famous are most common reasons for misconduct. Sometimes the laziness of person involved in research can be the reason for misconduct especially in case of complex study design and repeated assessments are involved. Previous studies suggest that misconduct also results when investigator strongly believes intuitively in the "right" answer despite the available evidence being contrary [27]. Misconduct can be innocent ignorance like backdating the signature on consent form where subject forgot to date the form initially, or even creating source documents from case record forms. Competition amongst staff including investigators, pressures for promotion, professional obligation and personality factors such as ego, need for recognition are some factors influence individual or organizations to involve in misconduct. There could also be associated environmental factors such as amount of oversight of the study, existence of explicit versus implicit rules, penalties and rewards attached to such rules, extent of training imparted, regulations involved and insufficient mentoring [28]. One of the reasons to expect research misconduct is the pressures to publish19 to increase the funding, and to meet expectations of organization or government.

Misconduct reporting is increasing, but yet difficult to ascertain whether this represents the true statistics. The declaration of codes of ethical research and training on research ethics and integrity cannot be expected to prevent all cases of misconduct. Some instances have more to do with distinctive moral values of individual rather than their intelligence. Education, training and intelligence do not go hand in hand with ethical values.

The true incidence is unknown; however there is strong evidence of under reporting. Published example of research misconduct include fabricating or falsifying research finding or data, engaging in fraud or deceit, putting patients in danger via inadequate research oversight or poor study design or ignoring adverse events, failing or forging to obtain consenting, engaging in multiple publications, accepting gift authorship, failing to declare interests, refusing to accept ethics committee oversight or to adhere to the approved protocol and failing to report or delaying the report of research findings [29]. The most common types of misconduct in clinical research are: Failure to follow an investigational plan; inadequate and inaccurate records; inadequate drug accountability; inadequate completion of informed consent forms; failure to report adverse drug reactions; failure to obtain and/or document subject consent; failure to notify an Institutional Review Board (IRB)/Ethics Committee (EC) of changes/progress reports; failure to obtain or document IRB approval [26].

There are different bodies like Officer for Human Research Protections in United States, which provides guidance, clarification on research subject protection. Another body Office of Research Integrity promotes integrity in research. Food and drug Administration (FDA) plays an important role in detection and prevention of fraud. FDA has the power to disqualify the investigator from taking part in further research if the site is not compliant with regulatory requirements and 
engaged with dishonest activity. However, the research institutes and universities have responsibility of taking actions against those found guilty. Danish committee on Scientific Dishonesty in Denmark was split into three groups often sit together to consider cases of fraud. In Norway, National Committee for the Evaluation of Dishonesty in Health Research reports findings to the involved parties and institution, and leaves any sanctions up to the employers. In Sweden, the responsibility of investigations remains with institutions, with an expert advisory group, linked to the Swedish Medical Research Council (MRC). In France, a principle medical body Delegation á l'Intégrité Scientifique (Delegation á Scientific Integrity) is responsible for both presentation of research fraud and sanction to be taken against institutions and individuals found guilty. In United Kingdom, National Panel for Research Integrity has been proposed as a joint venture between Department of Health and UK universities to provide independent support to the Health and Biomedical Sciences Research Community to establish and demonstrate effective systems for research integrity [2].

More recently, many reports have been published internationally which reflect badly on the medical profession's conduct in medical research. These include the deaths of Ellen Roche (a healthy volunteer given inhaled hexamethonium in an asthma study) [30] and 18-yearold Jessie Gelsinger (in a gene therapy trial) [31]. Other reports include: the US researcher who failed to abide by international standards while undertaking research in India [32]; the vision researcher who falsified 21 charts [33]; The doctor who resigned from his research institution and returned to private medical practice, thus avoiding the repercussions of a research scandal [34].

Accusing of misconduct initiates a painful process that can disturb one's career and research. Allegation of scientific fraud can affect careers of accuser and accused both in a different ways such as bring an institution's functions to a halt, divide faculties, negative media coverage etc. It can leads to loss of confidence in the entire research enterprise when the scientific establishment is unprepared. Some Researcher can still be reluctant despite of repeated demonstration of such case. A common thing is that researchers and institutions often react with denial and anger when faced with allegation of research misconduct. In many countries, the official response of the institution does not lead to effective action. Rennie has noted that one reason of response failure is the assessment by 'scientific dialogue' model does not work, as this model is assessment of allegation by peers, who are unfamiliar with legal principles. And legal model based on administrative law is more likely to be effective [35,36].

The quality at site is usually judged by inspections and audits. There has been as high as $23 \%$ (official action indicated) for cause inspections conducted by US FDA over the last several years [37]. The monitor should be looking at data closely which can help to identify red flags and warning signals. For example, the patient seen at site excessive instances of perfect attendance on scheduled day could be falsified data. The most important red flag include $100 \%$ drug compliance, no serious adverse event, identical result on electrocardiogram etc. [27]. Certain behaviour of site staff should raise suspicion even is they may not indicate any kind of misconduct. For example, major difference in trends at the site from other sites, very few or no adverse events being reported, fast recruitment or very few withdrawals, all drugs being dispensed in a similar manner (e.g., all tubes of cream dispensed being pressed at the same point), postponement of meeting or monitoring visits etc. [38]. These are some indicators for a monitor to look at site more vigilant.
Responses to scientific misconduct should cover prevention and deterrence both. In previous studies suggest that prevention should cover steps such as providing education and training to researchers, assisting and protecting whistle-blowers, instituting processes to adequately and promptly investigate and deal with allegations, clear ethical standards, encouraging practices which might reduce publication pressures on researchers, imposing better controls on industry sponsors of research and having adequate deterrents, including publicity conducted investigations and adequate sanctions.

Formal bodies responsible for managing scientific misconduct are not established in India. So the counties like India with unofficial mechanisms for examine allegations-it may be valuable to consider the different procedures and model. The most common setup is institutional, which is in most of the cases unprepared and ad hoc if an allegation arises in a university or other institution. The initial reaction of tackling allegation is often an official denial, or at least deep silence. If the allegation or case cannot remain in dark, then the institution sometimes reacts aggressively with authorization to show its high moral standards, despite the earlier case. One major problem with such establishment is internal distribution of power between scientists and leaders may represent a bias against justice.

The alternative to institutional set up is national or regional independent committees. This can be established in two principal ways - either on a legal basis or created by research councils, scientific and academies in common. Further, its responsibility may be restricted to biomedical research or be extended to cover all kinds for example humanities, social and technical science. If such committee only inquires and investigate, but do not deal with sanctions, at least part of the harmony is split into its individual components. Such committee can also take further steps to secure both accused and the whistleblower a high degree of fairness. If committee decides to take investigation, it will establish an independent specialist team to investigate on the case, and will prepare report which will be open for comment from all involved parties. The conclusion will be shared with parties and institution. The latter decides on sanctions if scientific dishonesty has been substantiated, and reports back to the committee so that any disparity between sanctions taken by different institutions can be minimized. Along with the investigative and evaluation process, independent committee's should focus on preventive values. Publicity about the individual cases has a vaccination effect in the research community, but this is enhanced if national and internal development is commented on in national committee's annual report.

Good science is dependent on reliable data. To ensure the integrity of research, the scientific community and regulatory take strong action against perceived research misconduct. There is no single way of dealing with research misconduct. Some counties have chosen a centralized approach while other has decentralized approach. However, all agree that the process needs to have certain features based upon concept of administrative law. Misconduct is being recognized as a criminal act by all nations, yet there are no international rules, which harmonize the management and regulation of clinical research misconduct or dishonesty.

Clinical research professionals may not understand ethical issues involved in conduct of clinical trials. Clinical trials in India also raise a concern whether the trial is relevant to the treatment of Indian population or it is just to provide a data to developed countries. Sometimes, India does not enjoy benefits of new treatment since the treatment is too expensive that Indian population may not afford or it might not be available in Indian market. Corrupt systems in India are 
one of the major causes of misconduct in trials. It is easy to get trial subjects where corrupt local government officials, local doctors and health authorities are eager to be paid off by good pharmaceutical companies and to have relationship with them. They can encourage whole provinces or villages to enrol in study.

Every country that conducts clinical research experiences the research misconduct. We cannot support the statement with certain evidence; however other countries have found it. Rather it would be weird if they did not find misconduct. Among countries that conduct scientific research, only few of them have coherent system for tracking and investigating the problem. Other countries, including India need a system for promotion of scientific integrity, providing research into misconduct, and detecting, investigating and punishing misconduct when it does occur. Further studies on reason and types of misconduct are needed to have better understanding on epidemiology.

India has no specific regulations pertaining to scientific fraud. Universities and sponsors or Institutions are responsible for investigating and taking action against misconduct, then they notify the same to Drug Controller General of India (DCGI). Misconduct is being recognized as a criminal act by all nations, yet there are no international rules, which harmonize the management and regulation of clinical research misconduct or dishonesty. However, many developed countries have established bodies and regulations to prevent and investigate scientific misconduct and fraud.

Fortunately, the result shows that misconduct is very rare in research, although there are considerable variations. Further studies on this topic are needed, but so far there is no evidence that trials have become ethically corrupt. Misconduct is rare, but cannot be ignored and should be control as soon as possible, because it can have tremendous impact. The most serious misconduct in clinical trials probably might not be serious but ethically significant.

All should come together to initiate the Summit for clinical research, including all stakeholders and representatives, patients, community representatives, funding agencies and Non-Government Organizations (NGOs). It will provide a platform for all to come together and to express what they see as negative and positive about existing system and they also can give their suggestions to make it better. This will improve public trust and ethical standard. This could be the best way to improve awareness among public and patients participating in clinical trials.

\section{Conclusion}

The previous studies on research misconduct and growing pressure on researchers suggest that scientific misconduct will not be vanished spontaneously. First of all we need to focus on prevention of various type of misconduct. In order to do so and to deal with allegations, government and other committees need to take steps such as better training and education for researcher, and legally sound processes for assessment of misconduct. Each instance of misconduct has potential to compromise patient safety which can lead to a loss of public confidence in the clinical research process and can prevent the research process. Any organization conducting or involved in clinical research must have polices at place that encourage disclosure of misconduct and to ensure that the accused researcher is not automatically stigmatized. Also there remains a need to establish an international harmonized approach to investigate, manage and prevent scientific misconduct. It is critical to develop culture of research which should be based on openness, honesty and basic fundamentals of integrity. Official bodies and committees should be at place in the country which can investigate clinical research misconduct. Regulator and open communication among research teal and groups on the important aspects of trial may help reduce the incidence of misconduct.

Increased awareness about misconduct should be created in India. Similar studies that might validate these findings in other groups would expand the circle of participants. Misconduct should be discussed in every available platform such as symposia, conference, lecture and other meetings. Research ethics and credible conduct of research should be incorporated into the curriculum of both undergraduate and postgraduate education.

\section{Suggestion for Future Research}

There is a lack of information on the prevalence of scientific misconduct from India. We need to conduct a study aiming at determination the prevalence of scientific misconduct in field of clinical research in India, and the factors associated with the prevalence needs to be discover. In our study we have included these aspects, but detailed research is needed on the same.

\section{References}

1. Shuster E (1997) Fifty years later: the significance of the Nuremberg Code. N Engl J Med 337: 1436-1440.

2. Ankier SI (2002) Dishonesty, misconduct and fraud in clinical research: an international problem. J Int Med Res 30: 357-365.

3. Millum J, Wendler D, Emanuel EJ (2013) The 50th anniversary of the Declaration of Helsinki: progress but many remaining challenges. JAMA 310: 2143-2144.

4. Hamblin TJ (1981) Fake. Br Med J (Clin Res Ed) 283: 1671-1674.

5. Franzen M, Rödder S, Weingart $P$ (2007) Fraud: causes and culprits as perceived by science and the media. Institutional changes, rather than individual motivations, encourage misconduct. EMBO Rep 8: 3-7.

6. Dyer O (2008) Psychiatrist admits plagiarism but denies dishonesty. BMJ 336: 1394-1395.

7. Fanelli D (2009) How many scientists fabricate and falsify research? A systematic review and meta-analysis of survey data. PLoS One 4: e5738.

8. Ferriman A (2000) Consultant suspended for research fraud. BMJ 321: 1429 .

9. Wilmshurst P (2007) Dishonesty in medical research. Med Leg J 75: 3-12.

10. Simpson JA, Weiner ES (1998) Oxford University Press. Oxford English dictionary. The Oxford English Dictionary. Clarendon Press, Oxford, UK.

11. U.S. DEPARTMENT OF HEALTH AND HUMAN SERVICES (1995) Integrity and Misconduct in Research. Report of the Commission on Research Integrity to the Secretary of Health and Human Services. USA.

12. Federal Register (2000) Executive Office of the President; Federal Policy on Research Misconduct; Preamble for Research Misconduct Policy, USA.

13. Smith R (2006) Research misconduct: the poisoning of the well. J R Soc Med 99: 232-237.

14. Norfolk and Suffolk NHS Foundation Trust (2014) Research Integrity, Fraud And Misconduct Policy.

15. Lock S (1988) Misconduct in medical research: does it exist in Britain? BMJ 297: 1531-1535.

16. Leach JP (1999) Lest we forgive. BMJ 319: 459.

17. Beecher HK (1966) Ethics and clinical research. N Engl J Med 274: 1354-1360.

18. Pappworth MH (1990) "Human guinea pigs"--a history. BMJ 301: 1456-1460. 
Citation: Patel M (2017) Misconduct in Clinical Research in India: Perception of Clinical Research Professional in India. J Clin Res Bioeth 8: 303. doi:10.4172/2155-9627.1000303

Page 9 of 9

19. Lock S, Wells F, Farthing M (2001) Fraud and Misconduct in Biomedical Research (3rd edn). London: British Medical Journal Publishing Group. UK.

20. Swan N (1996) Baron Munchausen at the lab bench? In: Lock, S, Wells, F, 2nd eds. Fraud and Misconduct in Medical Research (2nd edn) London: BMJ Publishing Group, UK.

21. Commission on Research Integrity (1996) Integrity and Misconduct in Research. Washington DC: Department of Health and Human Services.

22. Council for the International Organizations of Medical Sciences (2002) International Ethical Guidelines for Biomedical Research Involving Human Subjects. Geneva: World Health Organization.

23. Medical Research Council of Canada (1998) Natural Sciences and Engineering Research Council of Canada, Social Sciences and Humanities Research Council of Canada. Code of Ethical Conduct for Research Involving Humans. Ottowa: Canadian Tri-Council.

24. National Health and Medical Research Council (1999) National Statement on Ethical Conduct in Research Involving Humans. Canberra: National Health and Medical Research Council.

25. Sheehan JG (2007) Fraud, conflict of interest, and other enforcement issues in clinical research. Cleveland Clinic Journal of Medicine 74: S6367.

26. Jessen J, Robinson E, Bigaj S, Popiolek S, Goldfarb NM (2007) Unreported clinical research fraud and misconduct. Journal of Clinical Research Best Practice 3: 1-5.

27. Weir C, Murray G (2011) Fraud in clinical trials: Detecting it and preventing it. Significance pp:164-168.
28. Habermann B, Broome M, Pryor ER, Ziner KW (2010) Research coordinators' experiences with scientific misconduct and research integrity. Nurse Research 59: 51-57.

29. Emanuel EJ, Patterson WB (1998) Scientific misconduct in cancer clinical trials. J Clin Oncol 16: 3433-3438.

30. Steinbrook R (2002) Protecting research subjects--the crisis at Johns Hopkins. N Engl J Med 346: 716-720.

31. Teichler Zallen D (2000) US gene therapy in crisis. Trends Genet 16: 272-275.

32. Kumar S (2001) US university finds scientist flouted rules for clinical trials. Lancet 358: 1791 .

33. Ready $\mathrm{T}$ (2001) Stiff penalty for vision researcher guilty of scientific misconduct. Nat Med 7: 8 .

34. Weber W (2000) European clinical research scandal investigators question self-regulation. Lancet 356: 53.

35. Rennie D (1998) Dealing with research misconduct in the United Kingdom. An American perspective on research integrity. BMJ 316: 1726-1728.

36. Smith R (1996) Time to face up to research misconduct. BMJ 312: 789-790.

37. Bhatt A (2011) Quality of clinical trials: A moving target. Perspect Clin Res 2: 124-128.

38. Huk JP, Huk J, Filip R (2010) Fraud and misconduct in clinical research. Journal of Pre-Clinical and Clinical Research 4: 158-160. 